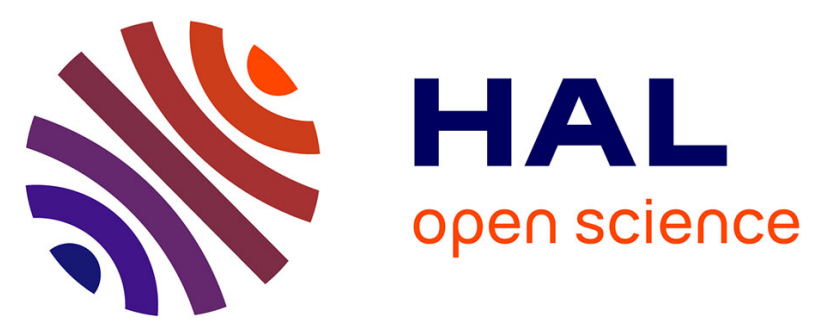

\title{
Exposure to the fungicide captan induces DNA base alterations and replicative stress in mammalian cells
}

\author{
Anne Fernandez-Vidal, Liana C. Arnaud, Manon Maumus, Marianne
}

Chevalier, Gladys Mirey, Bernard Salles, Julien Vignard, Elisa Boutet-Robinet

\section{To cite this version:}

Anne Fernandez-Vidal, Liana C. Arnaud, Manon Maumus, Marianne Chevalier, Gladys Mirey, et al.. Exposure to the fungicide captan induces DNA base alterations and replicative stress in mammalian cells. Environmental and Molecular Mutagenesis, 2019, 60 (3), pp.286-297. 10.1002/em.22268 . hal02620276

\section{HAL Id: hal-02620276 \\ https://hal.inrae.fr/hal-02620276}

Submitted on 17 Jun 2021

HAL is a multi-disciplinary open access archive for the deposit and dissemination of scientific research documents, whether they are published or not. The documents may come from teaching and research institutions in France or abroad, or from public or private research centers.
L'archive ouverte pluridisciplinaire HAL, est destinée au dépôt et à la diffusion de documents scientifiques de niveau recherche, publiés ou non, émanant des établissements d'enseignement et de recherche français ou étrangers, des laboratoires publics ou privés. 


\title{
Exposure to the fungicide captan induces DNA base alterations and replicative stress in mammalian cells
}

\author{
Anne Fernandez-Vidal ${ }^{1}$, Liana C. Arnaud ${ }^{1}$, Manon Maumus ${ }^{1}$, Marianne Chevalier ${ }^{1}$, \\ Gladys Mirey ${ }^{1}$, Bernard Salles ${ }^{1}$, Julien Vignard ${ }^{1 *}$ and Elisa Boutet-Robinet ${ }^{1 *}$ \\ ${ }^{1}$ Toxalim (Research Centre in Food Toxicology), Université de Toulouse, INRA, ENVT, INP-Purpan, \\ UPS, Toulouse, France \\ * Corresponding authors: \\ elisa.boutet@univ-tlse3.fr, telephone: + 33582066344 \\ julien.vignard@inra.fr \\ TOXALIM UMR 1331, 180 Chemin de Tournefeuille, BP 93173, F-31027 Toulouse cedex 3, France.
}

Running title: Base alterations and replicative stress induced by captan

Keywords:

Pesticide, captan, replicative stress, DNA damage, XRCC1 


\begin{abstract}
The classification of the fungicide captan (CAS Number: 133-06-2) as a carcinogen agent is presently under discussion. Despite the mutagenic effect detected by the Ames test and carcinogenic properties observed in mice, the genotoxicity of this pesticide in humans is still unclear. New information is needed about its mechanism of action in mammalian cells. Here we show that Chinese Hamster Ovary (CHO) cells exposed to captan accumulate Fpg-sensitive DNA base alterations. In CHO and HeLa cells, such DNA lesions require the XRCC1-dependent pathway to be repaired and induce a replicative stress that activated the ATR signalling response and resulted in double-strand breaks and micronuclei. The replicative stress is characterized by a dramatic decrease in DNA synthesis due to a reduced replication fork progression. However, impairment of the XRCC1-related repair process did not amplify the replicative stress, suggesting that the fork progression defect is independent from the presence of base modifications. These results support the involvement of at least two independent pathways in the genotoxic effect of captan that might play a key role in carcinogenesis.
\end{abstract}




\section{Introduction}

Captan is an agricultural fungicide that belongs to the phthalimide family. It was first registered in 1951 for tree fruit use and has been used commercially for over 60 years. Despite extensive studies its toxicity is still not consensual and it has been classified in several ways. It was classified in 1982 by the International Agency for Research on Cancer (IARC) as group 3 "Not classifiable as to its carcinogenicity to human" (IARC (International Agency for Research on Cancer) 1982). In the United States, the Environmental Protection Agency (EPA) reclassified it in 2004 it from "probable human carcinogen" to "not likely carcinogenic to human" (Gordon 2007). In contrast, it is classified in category 2 H351 ("suspected of causing cancer") according to the European regulations (European Commission, EC Reg $\mathrm{N}^{\circ} 1272 / 2008$ ). Captan is authorised in many countries. It is used mainly on fruits such as apples and is detected as pesticide residues in food in European countries (Crepet et al. 2013; Lozowicka 2015).

Concerning occupational exposure, a recent analysis from the North American Pooled Project showed that captan is associated with an increased risk of multiple myeloma in farmers (odds ratio 3.14 with a confidence interval $95 \%$ of 1.30-7.58) (Presutti et al. 2016). However, this risk is reduced for duration of exposure greater than 7 years (Presutti et al. 2016). Moreover, this non-monotonic exposure response pattern and the previous absence of association between the highest level of captan exposure and risk of cancer revealed by the Agricultural Heath Study (AHS) (Greenburg et al. 2008) contributed to the US EPA revision in 2004. A risk assessment study was conducted by the European Food Safety Authority (EFSA) in 2009 which concluded in its non-genotoxic potential (European Food Safety Authority 2009). However, the mutagenic potency of captan has long been reported in Ames strains TA1535 and TA104 and also in the Escherichia coli WP2uvrA strain (Bridges 1975; Barrueco and de la Pena 1988; Ohta et al. 2002), revealing base-change substitution on AT or GC base pairs, as well as in mammalian cellular mutation assays (O'Neill et al. 1981; Edgar et al. 1985). In addition to its mutagenic activity, the genotoxic potential of captan is supported by the induction of DNA breaks leading to chromosomal aberrations in mammalian cells (Swenberg et al. 1976; Tezuka et al. 1980; Snyder 1992). Finally, a direct interaction of captan with DNA and/or proteins linked to chromatin 
such as histones, polymerases or topoisomerase II, has been suggested (Anderson and Rosenkranz 1974; Couch and Siegel 1977; Couch et al. 1977; Selsky and Matheson 1981; Dillwith and Lewis 1982; Pritchard and Lappin 1991; Snyder 1992; Grilli et al. 1995; Provan et al. 1995; Provan and Eyton-Jones 1996; Rahden-Staron 2002).

In contrast to cellular analyses, carcinogenesis assays were negative in rats and slightly positive in mice, which developed duodenal glandular tumors and squamous cell lesions of the forestomach [see for review (Cohen et al. 2010)]. The difference observed in genotoxicity and mutagenesis between in vitro and in vivo situations might depend on the metabolism of captan and sequestration of reactive derivatives [for review see (Arce et al. 2010)]. Under in vivo conditions, the presence of thiol-rich environment such as cysteine or glutathione found in blood or liver, could explain the absence of genotoxicity by the quickly elimination of the reactive and volatile breakdown product of captan, the thiophosgene (Swenberg et al. 1976; Moriya et al. 1978; Gordon 2010). Thus, the increased tumour risk observed in mice might be due to chronic mucosal wounding and regenerative hyperplasia (Arce et al. 2010; Thompson et al. 2017), leading to non-genotoxic effects inducing duodenal carcinogenesis. Nevertheless, Mac Cauley and colleagues have described a significant positive association between DNA damage in oral human leukocytes using alkaline comet assay and urinary concentration of the captan metabolite tetrahydrophthalimide (McCauley et al. 2008).

In this context, it is of great interest to throw new light on captan mechanisms of toxicity. To this end, we investigated captan potential genotoxicity in mammalian in vitro cell lines. Here, we show that captan induces DNA damage that requires a XRCC1-dependent repair process and an independent replicative stress characterized by a slowing down of fork velocity, resulting in the formation of double-strand breaks (DSBs) and genomic instability.

\section{Material and methods}

\subsection{Cell lines and treatments}

HeLa human cells were maintained in Dulbecco's modified Eagle's medium (DMEM, Gibco, Life technologies). AA8 $\left(\mathrm{XRCC1}^{+/+}\right)$and $\mathrm{EM} 9\left(\mathrm{XRCC1}^{-/-}\right)$rodent cell lines were maintained in a mixture of 
50\% DMEM media and 50\% F-12 media. All media were supplemented with $10 \%$ heat-inactivated calf serum and $0.5 \mathrm{mg} / \mathrm{ml}$ penicillin/streptomycin $(\mathrm{P} / \mathrm{S})$. Cells lines were grown in a humidified incubator at $37{ }^{\circ} \mathrm{C}$ with $5 \% \mathrm{CO}_{2}$. All cell lines were checked and were mycoplasma-free. Peripheral Blood Mononuclear cells (PBMC) collected from one volunteer [Établissement Français du Sang, (EFS), written consent for the use of blood samples for the research protocol obtained according to the regulation for blood transfusion of the French blood organization EFS, Toulouse (France)] were Ficollseparated from whole blood and aliquoted $\left(1 * 10^{6}\right.$ cells/aliquot) prior to cryopreservation in liquid nitrogen as described previously (Lebailly et al. 2015). For each experiment, aliquots of PBMC were defrosted, washed with phosphate-buffered saline (PBS) with 10\% serum, centrifuged (200g, $10 \mathrm{~min}$ ) and resuspended in PBS. When needed, cells were treated with captan (Dr. Ehrenstorfer GmbH, Germany/CIL-Cluzeau; purity of $98.5 \%$, with impurities as inorganic salts, besides $0.02 \%$ ethanol and $0.01 \%$ dichloromethane). Captan was added to culture medium, supplemented with serum for all experiments, except for comet assays experiments, which were carried out without serum.

To induce DNA damage as products of purine oxidation detectable by formamidopyrimidine-DNA glycosylase (Fpg), cells were placed on ice and treated with the compound Ro 19-8022 (gift from Hoffman Laroche Ltd) (at $1 \mu \mathrm{M}$ in PBS) for $2 \mathrm{~min} 30 \mathrm{sec}$ under visible light (1000 W-halogen). Ro 19-8022 plus light is an appropriate positive control for the Fpg-modified comet assay (Azqueta et al. 2013).

\subsection{RNA interference}

Gene silencing was performed by transfection of siRNA (Sigma-Aldrich) in HeLa cells with INTERFERin ${ }^{\circledR}$ according to the manufacturer's instructions (Polyplus). Briefly, siRNA were mixed with interferin in Opti-MEM and incubated for 10 minutes at room temperature. Then, HeLa cells were transfected with the negative control siRNA (CAUGUCAUGUGUCACAUCU-dTdT), or with siRNA directed against XRCC1 (GGAAGAUAUAGACAUUGAG-dTdT), or ATR (CCUCCGUGAUGUUGCUUGA-dTdT). After 24 hours of incubation, cells were counted and plated for further analysis. 


\subsection{Clonogenic assay}

Cells were plated in triplicate at a density of 200 to 500 cells per well in 6-well plates. One day after seeding, cells were treated with captan at the indicated concentrations in complete medium and grown for 6-12 days. AA8 and EM9 cells were exposed to captan until fixed. For HeLa cells treated with siRNA, cells were exposed to captan 66 hours to 90 hours post-transfection during the most efficient time of siRNA-mediated protein depletion. Formed colonies were fixed and stained with a $0.25 \%$ methylene blue (Sigma) and 50\% methanol solution. Colonies containing more than 50 cells were counted and the survival rate calculated. Survival rates are normalized to $100 \%$ for undamaged cells for each cell population.

\subsection{Proliferation assay}

Cells were plated in duplicate in 24-well plates at a density of 40,000 and 50,000 cells per well for AA8 and EM9 cells, respectively. One day after seeding, cells were treated in duplicate with captan at the indicated concentrations in complete medium and grown for 48 hours. Final cell number in each well was estimated by Malassez cell counting.

\subsection{Micronucleus assay}

HeLa cells were grown in 12-well plates $\left(2 \times 10^{4}\right.$ cells/well) for 24 hours before to be treated or not with captan for 24 hours. AA8 and EM9 cells were grown in 24-well plates $\left(2 \times 10^{4}\right.$ cells/well $)$ for 24 hours before to be treated with captan for 24 hours. Cells were fixed with $4 \%$ paraformaldehyde for 20 min after a PBS wash. They were then permeabilized with $0.5 \%$ Triton X-100 in PBS for 15 min, and nuclei were stained with 4.6-diamino-2-phenyl indole (DAPI) (100 nM).

\subsection{Comet assay}

The alkaline comet assay was used to detect strand breaks and alkali-labile sites as previously described with minor modifications (Lebailly et al. 2015). Cells were embedded in $0.7 \%$ low melting point agarose and a parallel digestion with Fpg enzyme (gift from Serge Boiteux, CNRS, France) allowing the detection of Fpg-sensitive sites was performed, as already described (Azqueta et al. 2013). Fifty cells per slide and 2 slides per sample were analysed. The extent of DNA damage was 
evaluated for each cell by measuring the intensity of all tail pixels divided by the total intensity of all pixels in the head and tail of the comet. The median of these 100 values was calculated and named $\%$ tail DNA. For comet cellular repair assay, the Net level of Fpg-sensitive sites (\% Tail DNA) was obtained for each condition by subtracting the damage (\% Tail DNA) obtained in the absence of Fpg from Fpg-exposed comets ("+Fpg" - "-Fpg" = Net Fpg). To specifically calculate the effect of captan (\% Tail DNA), Net Fpg-sensitive sites of non-treated (control) cells was subtracted from Net Fpgsensitive sites of captan treated cells, corresponding to Net Fpg-sensitive sites above the control cells (Net Fpg of captan - Net Fpg of control cells = Net Fpg of captan above control).

\subsection{Immunofluorescence analysis}

Cells were grown on glass coverslips. After at least 24 hours of culture, cells were fixed with $4 \%$ paraformaldehyde, permeabilized with $0.5 \%$ Triton X-100 for 15 minutes, blocked in 3\% BSA and stained with primary antibodies (dilution 1:3000) overnight at $4{ }^{\circ} \mathrm{C}$ in blocking solution. For FANCD2 detection, a pre-extraction step ( $0.5 \%$ Triton $\mathrm{X}-100$ for 5 minutes) was performed before fixation. 53BP1 (NB100-304) and FANCD2 (NB100-182) antibodies were purchased from Novus Biologicals and $\gamma \mathrm{H} 2 \mathrm{AX}$ antibody from Merck/Millipore (05-636). Cells were washed three times with PBS Tween $0.1 \%$ and incubated with the secondary antibodies (dilution 1:800) for 1 hour (Rhodamine Red X (R6394) and AlexaFluor 488 Goat anti-mouse (A11017) or anti-rabbit (A11070), purchased from Invitrogen). DNA was stained with DAPI. Cells were counted positive for $\gamma \mathrm{H} 2 \mathrm{AX}$ and 53BP1 foci formation when $>10$ foci/nuclei were detected and counted positive for FANCD2 when $>3$ foci/nuclei were detected.

\subsection{Flow cytometry analyses}

\subsection{1 $\gamma \mathrm{H} 2 \mathrm{AX}$ staining}

Two hours after treatment with $10 \mu \mathrm{M}$ captan, AA8 and EM9 cell lines were fixed in PBS containing $4 \%$ paraformaldehyde for $15 \mathrm{~min}$ at room temperature, washed, then permeabilized with PBS containing $0.2 \%$ triton $\mathrm{X}-100$ and $1 \% \mathrm{BSA}$ for $20 \mathrm{~min}$ at room temperature. Antibody against $\mathrm{\gamma H} 2 \mathrm{AX}$ (1:300, clone JBW301, Millipore) was incubated for 3 hours in PBS containing 1\% BSA at room temperature. After three washes, cells were incubated with the secondary antibody anti-mouse Alexa 
Fluor 488 (1:1000, A11017, Thermofisher) for $30 \mathrm{~min}$ at room temperature. Then, cells were washed three times and incubated in PBS containing DAPI $(1 \mu \mathrm{g} / \mathrm{ml})$ for $15 \mathrm{~min}$ before samples were processed using flow cytometry (MACSQuant, Miltenyi Biotec). At least 10,000 events were analysed per sample using FlowJo software.

\subsubsection{Cell cycle analysis}

Two hours after captan treatment $(10 \mu \mathrm{M}), \mathrm{CHO}$ cell lines were incubated with EdU $(5 \mu \mathrm{M})$ for 15 min. Cells were collected by trypsinization and incorporated EdU was detected using the baseclick EdU flow cytometry kit (Sigma, BCK-FC488) according to the manufacturer's instructions. Cells were incubated in PBS containing DAPI $(1 \mu \mathrm{g} / \mathrm{ml})$ for 15 min before samples were processed using flow cytometry (MACSQuant, Miltenyi Biotec). At least 10,000 events were analysed per sample using FlowJo software.

\subsection{DNA fibre assay}

CHO cell lines were plated for 24 hours before sequential pulse labelling with $50 \mu \mathrm{M}$ CldU (5chlorodeoxyuridine, Sigma-Aldrich), then $100 \mu \mathrm{M}$ IdU (5- iododeoxyuridine, Sigma-Aldrich) for 20 min each, followed by a chase with $200 \mu \mathrm{M}$ thymidine (Sigma-Aldrich) for 1 hour. Then, cells were collected for DNA fibre assays and re-suspended in cold PBS. Two $\mu$ l of cells resuspended in PBS $\left(5 \times 10^{5} \mathrm{cells} / \mathrm{ml}\right)$ were spotted onto clean glass slides, mixed with $7.5 \mu \mathrm{l}$ of lysis buffer $(200 \mathrm{mM}$ Tris$\mathrm{HCl} \mathrm{pH} \mathrm{7.4,} 50 \mathrm{mM}$ EDTA, 0.5\% SDS) and incubated horizontally for $5 \mathrm{~min}$ at room temperature. DNA was spread by tilting the slide manually at a $30-45^{\circ}$ angle. The air-dried DNA was fixed in cold methanol/acetic acid (3:1) for $20 \mathrm{~min}$. Slides were rehydrated in PBS twice and the DNA was denatured in $2.5 \mathrm{M} \mathrm{HCl}$ for $45 \mathrm{~min}$ at room temperature. The slides were washed twice in PBS, followed by incubation in blocking solution (1\% BSA, $0.1 \%$ Tween 20, PBS) for $30 \mathrm{~min}$ at room temperature followed by primary antibodies (rat anti-CldU (1:75, OBT0030G, Biorad) and mouse anti-IdU (1:50, BD347583, Becton Dickinson)) for 1.5 hours at room temperature. After three washes in PBS, the slides were fixed in $4 \%$ paraformaldehyde for $10 \mathrm{~min}$, washed and then incubated in blocking solution for $10 \mathrm{~min}$. Next, the slides were incubated with the secondary antibodies (anti-rat Alexa Fluor 546 (A11081) and anti-mouse Alexa Fluor 488 (A11017), Thermofisher, 1:200) for 1 
hour at room temperature. Subsequently, they were washed as before, incubated in blocking solution for $10 \mathrm{~min}$, then with the single-strand DNA antibody overnight at $4^{\circ} \mathrm{C}$ (mouse-anti ssDNA, 1:50, MAB3034, Millipore). After three washes in PBS, the slides were incubated in blocking solution for 10 min and finally with the secondary antibody (anti-mouse Alexa Fluor 350, 1:200, A21130, Thermofisher) for 2 hours. Images were analysed using NIS Elements-AR Nikon software. The specific DNA staining allowed the exclusion of any signal due to broken or overlapping DNA fibres. IdU track length was determined if flanked by a CldU track. At least 400 fibres per condition were measured.

\subsection{Western blot analysis}

Cells were incubated on ice for $30 \mathrm{~min}$ in lysis buffer $(50 \mathrm{mM}$ Tris- $\mathrm{HCl} \mathrm{pH} 7.5,250 \mathrm{mM} \mathrm{NaCl}$ and 0.5\% NP40) containing the HaltTM Protease \& Phosphatase inhibitor cocktail (Thermo Scientific) and sonicated. Cell lysates were centrifuged and the supernatant containing total soluble proteins was kept. Proteins were separated by SDS-PAGE and transferred to a nitrocellulose membrane (Amersham). Membranes were incubated with the primary antibody for a period of 1-16 hours. Chk1 (2G1D5) and pChk1 (133D3) antibodies (dilution 1:1000) were purchased from Cell Signalling, ATR (SAB4200348, dilution 1:500) and Lamin A/C (SAB4200236, dilution 1:1000) antibodies from Santa Cruz, XRCC1 antibody (X0629, dilution 1:1000) from SIGMA, FANCD2 antibody (NB100-182, dilution 1:5000) from Novus Biologicals, and GAPDH (GTX100118, dilution 1:50000) antibody from GeneTex. The secondary anti-mouse or anti-rabbit HRP-conjugated antibodies (Jackson Immunoresearch laboratories) were incubated for 1 hour at room temperature. Proteins were visualised with the enhanced chemiluminescence substrate ECL (Biorad) and imaged using the ChemiDoc XRS Biorad Imager and Image Lab Software. Lamin, Chk1 and GAPDH were used as internal control.

\subsection{Statistical analysis}

The results are expressed as the mean \pm SEM. Statistical analysis was assessed using Prism 6 software (GraphPad). Student's t-test, Mann-Whitney or two-ways ANOVA tests, followed by post hoc tests were used when appropriate. A P value $<0.05$ was considered significant. For clonogenic survival assay, micronucleus assay, $\gamma \mathrm{H} 2 \mathrm{AX}$ and 53BP1 immunofluorescence analyses on siRNA- 
transfected HeLa and CHO (AA8 and EM9) cells, two-way ANOVA followed by Sidak's multiple comparison test were used in order to study treatment effects and cell line effect. This statistical approach was also used for $\gamma \mathrm{H} 2 \mathrm{AX}$ staining analysed by flow cytometry and cell cycle analysis. For the analysis of "Fpg sensitive sites" by comet assay, two-tailed Student's t-test was used. For the other comet assays, two-way ANOVA followed by Sidak's multiple comparison tests were performed. For DNA fibre assay, statistical analysis was performed using two-tailed Mann-Whitney test.

\section{Results}

\subsection{XRCC1 deficiency induces hypersensitivity to captan}

Since captan was reported to induce base substitution reversion in Ames test strains (TA102 and TA104) and WP2uvrA6 Escherichia coli strains used to detect base substitution mutagenesis, we first tested the effect of XRCC1 defect, a scaffold protein involved in base excision repair (BER) (Kubota et al. 1996). HeLa cells were depleted for XRCC1 protein by transfection with siRNA (Fig. 1A, left panel). Compared to control cells transfected with a scramble siRNA, XRCC1-deficient cells showed a significant higher sensitivity to $1 \mu \mathrm{M}$ of captan (Fig. 1A, right panel). Similarly, EM9 CHO cells mutated in XRCC1 were more sensitive than the wild type AA8 cells to captan treatment (Fig. 1B). These results suggest that captan sensitivity is associated with the induction of DNA damage that is repaired by XRCC1. HeLa cells exposed to $10 \mu \mathrm{M}$ of captan for 24 hours exhibited a higher percentage of micronucleus-containing cells compared to untreated cells (Fig. S1), suggesting that captan induces DNA damage that can generate genetic instability. Moreover, AA8 and EM9 CHO cells exposed to captan for 24 hours exhibit a dose-dependent increase of micronucleus formation, with a significant greater impact on EM9 cells (Fig. 1C). This data demonstrate that XRCC1 is involved in the prevention of genetic instability induced by captan.

In order to confirm that captan induces DNA damage in mammalian cells, an alkaline comet assay was performed on human peripheral lymphocytes. When exposed to $1 \mu \mathrm{M}$ of captan for 2 hours, these lymphocytes present more DNA damage than the non-treated cells (Fig. S2), confirming the genotoxic 
activity of the fungicide. Then, the involvement of XRCC1 in the repair of DNA damage induced by captan was analysed through alkaline and Fpg-modified comet assays. In CHO cells exposed to $1 \mu \mathrm{M}$ of captan for 2 hours, no damage was observed through alkaline comet assay (Fig. 1D), probably due to the high basal DNA damage already detected in this cellular background. In the same way, no DNA damage through alkaline comet assay can be observed in these cells treated with Ro 19-8022, a chemical agent known to generate 8-oxoguanine (Fig. S3A). Next, the Fpg-modified comet assay was performed to reveal Fpg-sensitive sites which mainly represent oxidative base modifications [Reviewed in (Collins 2014)], usually repaired by the BER pathway. Similar to the control treatment with Ro 19-8022 (Fig. S3A), captan exposure for 2 hours induced Fpg-sensitive DNA lesions, as shown in AA8 and EM9 CHO cells (Fig. 1D). To determine whether XRCC1 is involved in the repair of such lesions, Fpg-modified comet assay was also performed on AA8 and EM9 CHO cells released for 1 hour in fresh media after captan or Ro 19-8022 exposure. In control cells, repair of DNA lesions induced by captan or Ro 19-8022 was almost complete within 60 minutes (Fig. 1E for captan and Fig. S3B for Ro 19-8022). In contrast, repair of Fpg-sensitive lesions was severely impaired in XRCC1deficient cells after captan or Ro 19-8022 exposure (Fig. 1E for captan and Fig. S3B for Ro 19-8022). These results indicate the involvement of XRCC1 in the repair of DNA damage induced by captan.

\subsection{The replicative stress response is crucial for survival from captan-related genotoxicity}

To further characterize the genotoxic stress induced by captan, we performed immunofluorescence in HeLa cells to analyse histone $\mathrm{H} 2 \mathrm{AX}$ phosphorylation ( $\mathrm{\gamma H} 2 \mathrm{AX}$ ), which is a general DNA damage marker mainly associated with DSBs and replication stress (RS), and 53BP1 recruitment, which is more specific to DSBs (de Feraudy et al. 2010; Vignard et al. 2013) (Fig. 2A). After 2 hours of captan exposure, a dose-dependent increase in both ${ }_{\gamma} \mathrm{H} 2 \mathrm{AX}$ - and 53BP1-positive cells was observed (Fig. 2B). Except for the non-treated condition where the ${ }_{\gamma} \mathrm{H} 2 \mathrm{AX}$ signalling may be too low in some cells to be properly detected, all the 53BP1 positive cells were also ${ }_{2} \mathrm{H} 2 \mathrm{AX}$ positive after captan treatment. However, a subclass of captan-treated cells accumulating a ${ }_{\gamma} \mathrm{H} 2 \mathrm{AX}$ signal was devoid of 53BP1 foci (Fig. 2A-B). This suggests that captan-related DNA damage generates a RS that subsequently results in DSB formation. To test this hypothesis, HeLa cells exposed to captan for 2 hours were co-labelled 
with $\gamma_{\mathrm{H}} 2 \mathrm{AX}$ and FANCD2, a protein that spontaneously form foci in S-phase cells (Liu et al. 2000; Taniguchi et al. 2002). As in non-treated HeLa cells where a weak $\mathrm{\gamma H}_{2} \mathrm{AX}$ staining related to a low RS signalling is only visible in FANCD2 positive cells, the increased subclass of cells accumulating yH2AX after captan exposure is limited to the FANCD2 positive population (Fig. S4). Taken together, these data suggest that captan-mediated DNA damage induces a RS and subsequently DSB signalling specifically during S-phase.

To investigate whether captan exposure induces RS, we assessed the induction of CHK1 phosphorylation at S345 (pCHK1) and of FANCD2 monoubiquitylation, two well-established markers of RS (Liu et al. 2000; Taniguchi et al. 2002). HeLa cells exposed to $20 \mu \mathrm{M}$ of captan for 2 hours exhibited higher pCHK1 and FANCD2 monoubiquitylation compared to non-treated cells, demonstrating that captan-exposed cells undergo RS (Fig. 2C). We next confirmed that the RS response is crucial after captan treatment by addressing the sensitivity of cells deficient in ATR, an essential kinase for surviving RS (Saldivar et al. 2017). As expected, siRNA-mediated ATR downregulation resulted in loss of viability in HeLa cells exposed to captan (Fig. 2D). Moreover, ATR-deficient cells treated with $10 \mu \mathrm{M}$ of captan for 24 hours presented a higher percentage of micronuclei compared to control cells (Fig. 2E), indicating that the RS response is important to prevent genetic instability after captan. In addition, the proportion of 53BP1-positive cells after captan exposure was higher after ATR depletion (Fig. 2F), providing further evidence that these DSBs derive from captan-induced RS. Taken together, these data demonstrate that captan exposure induces an RS that requires ATR to prevent DSB formation and genetic instability.

\subsection{Captan impairs replication fork progression in an XRCC1-independent manner}

The early RS induced by captan should rapidly mitigate the proliferative rate of exposed cells. Remarkably, AA8 and EM9 CHO cells treated with captan for 48 hours show a similar dosedependent proliferation defect (Fig. S5), suggesting that the captan induced RS does not merely relies on the presence of the DNA lesions that require XRCC1 to be repaired. To obtain better insights into the RS induced by captan and investigate the impact of XRCC1 deficiency in this process, we analysed ${ }_{\gamma} \mathrm{H} 2 \mathrm{AX}$ distribution through the cell cycle by flow cytometry in AA8 and EM9 CHO cells. 
We observed a significant increase in ${ } \mathrm{H} 2 \mathrm{AX}$ staining in the $\mathrm{S}$ phase of both cell lines in the same range, mostly at the onset of the S phase (Fig. 3A). These data confirm the RS induction by captan highlighted in figure 2 but suggest that it could be independent of the repair defects caused by XRCC1 deficiency. Then, we assessed the impact of captan treatment on the cell cycle, especially in the $S$ phase, by performing EdU incorporation experiments followed by flow cytometry analysis. In the absence of treatment, almost all AA8 and EM9 CHO cells in the S phase incorporated EdU (Fig. 3B). However, captan induced a huge loss of global EdU intensity only 2 hours after treatment (Fig. 3B and Fig. S6). Consequently, the proportion of EdU-negative $S$ phase cells increased significantly in the same range in both cell lines (Fig. 3B). Impairment of EdU incorporation during replication suggests a slowing down of replication fork velocity. To directly address this question, we performed DNA fibre assays by successive double-pulse labelling with two nucleotide analogues, CldU followed by IdU incorporation, to measure replication fork speed in the DNA fibre. AA8 and EM9 CHO cell lines were treated with captan only during the second pulse labelling (IdU incorporation) and the track lengths were measured (Fig. 3C). We observed a significant decrease in IdU track length, reflecting a slowing down of replication fork velocity in the presence of captan. Moreover, the decrease in replication fork speed was similar between AA8 and EM9 cells, suggesting that the captan-related replication fork slowdown is independent of the repair defects caused by XRCC1 deficiency. To test whether XRCC1 could influence the fork restart, we performed a DNA fibre assay on AA8 and EM9 CHO cell lines exposed to captan only during the first pulse labelling (CldU), then quantified the fork restart by measuring the IdU track length (Fig. 3D). As shown, the replication fork restart was similar in both cell lines, suggesting that XRCC1 depletion does not affect the replication fork restart. Altogether, these results demonstrate that during the $\mathrm{S}$ phase, captan exposure inhibits replication fork progression, leading to $\mathrm{H} 2 \mathrm{AX}$ phosphorylation, independently of BER pathway. 


\section{Discussion}

Despite the mutagenic effect of captan reported on bacteria testing strains [e.g. see (Bridges 1975; Barrueco and de la Pena 1988; Ohta et al. 2002)], the genotoxic effect of captan on eukaryotic cells, and in particular on human cells, is still under debate.

Our data indicate that the susceptibility of mammalian cells to captan is linked to its genotoxic potential, as revealed by the sensitivity of XRCC1-deficient cells. XRCC1 polymorphism has been associated with a higher risk of cancers (Hu et al. 2005; Hung et al. 2005). We show here that in absence of XRCC1, captan exposure of mammalian cells induces more micronucleus formation, indicating that XRCC1 may prevent genetic instability after captan. Indeed, XRCC1 plays a major role in maintaining chromosomal stability, its deficiency leading to an elevated level of sister chromatid exchange and chromosomal aberrations (Thompson et al. 1982; Zdzienicka et al. 1992). XRCC1 is a scaffold protein that interacts with different components of the BER machinery to stabilize or stimulate them (Caldecott 2014). BER is a versatile system capable of dealing with a broad range of base modifications, including oxidation, alkylation or deamination as well as abasic sites and singlestrand breaks (Krokan and Bjoras 2013). The modified alkaline comet assay allowed us to shed the light on the presence of Fpg-sensitive DNA sites after captan exposure. As Fpg is a bacterial glycosylase mainly active across oxidized purines (Boiteux et al. 2017), our results corroborate bacterial mutagenicity studies with strains that detect oxidative compounds. Moreover, the sensitivity and the repair defects of $\mathrm{CHO}$ cells defective in XRCC1 protein demonstrate the role of BER in overcoming the genotoxic effect of captan. The XRCC1 deficient EM9 cells show moderate hypersensitivity to captan, which might suggest that other DNA repair pathways could be required to survive captan exposure. However, EM9 cells have previously been reported to exhibit massive or slight hypersensitivity to base modifications depending on the ROS-generating or methylating agent, which may be correlated to differential XRCC1 requirement in many BER sub-pathways implying different DNA glycosylases (Barrows et al. 1991; Horton et al. 2008). While the highlighting of Fpgsensitive sites and the moderated sensitivity of XRCC1 deficient cells after captan exposure argue for the formation of oxidized bases such as 8-oxoguanine, our data cannot exclude that other lesions such 
as alkylated bases are induced. Further studies will be necessary to better characterize the base lesions induced by captan and the cellular mechanisms involved for repair. In summary, these results indicate that captan induces Fpg-sensitive DNA lesions in mammalian cells, presumably altered bases, which require an XRCC1-dependent BER process to be repaired, as depicted in the model (Fig. 4). The cellular consequences of captan genotoxicity were first analysed by co-immunodetection of ${ }_{\gamma} \mathrm{H} 2 \mathrm{AX}$ and 53BP1. After captan exposure, HeLa cells accumulated more $\mathrm{\gamma H}^{\mathrm{H}} \mathrm{AX}$ - than 53BP1positive cells. 53BP1 is specifically recruited to DSBs (Schultz et al. 2000), whereas $\gamma \mathrm{H} 2 \mathrm{AX}$ can form foci after RS independently of DSB formation (Ray Chaudhuri et al. 2012). This suggests that captan induces an RS that may subsequently result in S-phase-dependent DSBs. Indeed, captan-treated HeLa cells rapidly exhibit enhanced Chk1 phosphorylation and FANCD2 monoubiquitinylation, two hallmarks of RS signalling (Liu et al. 2000; Taniguchi et al. 2002). These data are strengthened by the role of ATR, the major kinase governing the cellular response to RS (Liu et al. 2000; Taniguchi et al. 2002) to survive captan exposure. Finally, the increase in micronuclei- and 53BP1-positive cells after captan exposure in ATR-deficient cells compared to control cells demonstrates that an effective RS response is necessary to prevent DSB formation and genetic instability in response to captan, as depicted in the model (Fig. 4). This indicates that the most dramatic cellular consequences of captan exposure arise during the $\mathrm{S}$ phase.

The latter finding prompted us to characterize the RS induced by captan in more detail. Furthermore, we wondered whether the induction of the Fpg-sensitive sites by captan sustains the replication defects. The slowing down of the replication fork observed from only 20 min after captan treatment was not exacerbated by XRCC1 deficiency. This suggests that in parallel to induction of the Fpg-sensitive DNA lesions detected by the Fpg-modified comet assay, captan also inhibits DNA replication, which is in good agreement with previous studies. Indeed, biochemical analyses have shown that captan could be a general inhibitor of both eukaryotic and prokaryotic DNA polymerases (Dillwith and Lewis 1982; Freeman-Wittig et al. 1989; Snyder 1992). These reports showed that the fungicide impairs initiation of polymerisation, but not the elongation step of DNA synthesis, in an irreversible manner by competing with DNA regarding polymerase loading. Consequently, dissociation of the polymerase from the DNA template would promote its inhibition by captan. This observation could explain the difficulties 
encountered by replicative forks to restart after captan treatment. It also raises the question of potential differences in captan sensitivity between replicative polymerases and specialized DNA polymerases, which are involved in DNA repair, translesion synthesis and replication. On the other hand, we cannot exclude that captan may induce different type of DNA lesions which repair is independent of XRCC1, and that may impede replication fork progression. Indeed, the repair of Fpg-sensitive sites induced by captan is less efficient than those induced by Ro 19-8022, suggesting a more complex situation. In the same way, the previously reported interaction of captan with DNA or proteins associated to chromatin (Arce GT 2010), such as the topoisomerase II inhibition by captan (Rahden-Staron 2002), may be responsible for the RS we report in this study. Further analyses on the possible role of other DNA repair pathways will be necessary to address these issues.

DNA strand breaks and micronuclei are induced as a consequence of RS, which in turn leads to genomic instability. Our study demonstrates that captan exposure in mammalian cells induces various genotoxic effects, corroborating previous in vivo reports (Legator 1969; Feng and Lin 1987; Snyder 1992) and suggesting that these mechanisms could play a role in carcinogenesis. Moreover, our in vitro results on human peripheral lymphocytes, showing DNA damage with alkaline comet assay after captan treatment (Fig. S2), corroborate human in vivo study which has reported a significant positive association between DNA damage using alkaline comet assay and urinary concentration of captan (McCauley et al. 2008). In view of recent epidemiological data pointing to a carcinogenic effect in farmers exposed to captan (Presutti et al. 2016), more data are needed to evaluate the human health risk that this fungicide potentially represents.

\section{Statement of author contributions}

AFV, JV and EBR designed the study. LCA, MM, MC, AVF, JV and EBR performed the experiments, analysed the data, prepared draft figures and tables. AFV, JV and EBR prepared the manuscript draft with important intellectual input from GM and BS. All authors approved the final manuscript. 


\section{Acknowledgments}

Dr. Sandrine Ellero-Simatos is greatly acknowledged for her advice on statistical analysis. The authors were supported by grants from the Cancer Plan for PestiBG ( ${ }^{\circ}$ ENV201401) (EBR).

\section{References}

Anderson M, Rosenkranz H. 1974. Greenhouse fungicide-environmental carcinogen. Henry Ford Hospital Medical Journal 22(1):35-40.

Arce GT, Gordon EB, Cohen SM, Singh P. 2010. Genetic toxicology of folpet and captan. Crit Rev Toxicol 40(6):546-574.

Azqueta A, Arbillaga L, Lopez de Cerain A, Collins A. 2013. Enhancing the sensitivity of the comet assay as a genotoxicity test, by combining it with bacterial repair enzyme FPG. Mutagenesis 28(3):271-277.

Barrows LR, Paxton MB, Kennedy KA, Thompson LH. 1991. Characterization of revertants of the CHO EM9 mutant arising during DNA transfection. Carcinogenesis 12(5):805-811.

Barrueco C, de la Pena E. 1988. Mutagenic evaluation of the pesticides captan, folpet, captafol, dichlofluanid and related compounds with the mutants TA102 and TA104 of Salmonella typhimurium. Mutagenesis 3(6):467-480.

Boiteux S, Coste F, Castaing B. 2017. Repair of 8-oxo-7,8-dihydroguanine in prokaryotic and eukaryotic cells: Properties and biological roles of the Fpg and OGG1 DNA N-glycosylases. Free Radic Biol Med 107:179-201.

Bridges BA. 1975. The mutagenicity of captan and related fungicides. Mutat Res 32(1):3-34.

Caldecott KW. 2014. DNA single-strand break repair. Exp Cell Res 329(1):2-8.

Cohen SM, Gordon EB, Singh P, Arce GT, Nyska A. 2010. Carcinogenic mode of action of folpet in mice and evaluation of its relevance to humans. Crit Rev Toxicol 40(6):531-545.

Collins AR. 2014. Measuring oxidative damage to DNA and its repair with the comet assay. Biochim Biophys Acta 1840(2):794-800.

Couch R, Siegel M. 1977. Interaction of captan and folpet with mammalian DNA and histones. Pesticide Biochemistry and Physiology 7(6):531-546.

Couch RC, Siegel MR, Dorough HW. 1977. Fate of captan and folpet in rats and their effects on isolated liver nuclei. Pesticide Biochemistry and Physiology 7(6):547-558.

Crepet A, Tressou J, Graillot V, Bechaux C, Pierlot S, Heraud F, Leblanc J. 2013. Identification of the main pesticide residue mixtures to which the French population is exposed. Environ Res 126:125-133.

de Feraudy S, Revet I, Bezrookove V, Feeney L, Cleaver JE. 2010. A minority of foci or pan-nuclear apoptotic staining of gammaH2AX in the $S$ phase after UV damage contain DNA doublestrand breaks. Proc Natl Acad Sci U S A 107(15):6870-6875.

Dillwith JW, Lewis RA. 1982. Inhibition of DNA polymerase by captan. Biochim Biophys Acta 696(3):245-252.

Edgar D, Bosworth H, Ransome S, Banks S, Hankinson K. 1985. An assessment of the mutagenic potential of Merpan technical using an in vitro mammalian cell test system. Report No $\mathrm{MSB} / 9 \mathrm{~A}$ from CRO: Huntington, Cambridgeshire, England: Huntingdon Research Centre Sponsor: Beer Sheva, Israel: Makhteshim Chemical Works Ltd December 16.

European Food Safety Authority. 2009. Conclusion regarding the peer review of the pesticide risk assessment of the active substance captan. EFSA Journal 7(8):296, 291-290.

Feng JY, Lin BY. 1987. Cytogenetic effects of an agricultural antibiotic, captan, on mouse bone marrow and testicular cells. Environ Res 43(2):359-363. 
Freeman-Wittig MJ, Welch W, Jr., Lewis RA. 1989. Binding of captan to DNA polymerase I from Escherichia coli and the concomitant effect on 5'----3' exonuclease activity. Biochemistry 28(7):2843-2849.

Gordon E. 2007. Captan: transition from 'B2' to 'not likely'. How pesticide registrants affected the EPA Cancer Classification Update. J Appl Toxicol 27(5):519-526.

Gordon EB. 2010. Captan and folpet. Hayes' Handbook of Pesticide Toxicology (Third Edition): Elsevier. p 1915-1949.

Greenburg DL, Rusiecki J, Koutros S, Dosemeci M, Patel R, Hines CJ, Hoppin JA, Alavanja MC. 2008. Cancer incidence among pesticide applicators exposed to captan in the Agricultural Health Study. Cancer Causes Control 19(10):1401-1407.

Grilli S, Moauro A, Mazzullo M. 1995. In vivo fluorimetric assay of DNA unwinding as evidence of the damage induced by folpet in rat liver DNA. Journal of Environmental Science \& Health Part A 30(5):1119-1127.

Horton JK, Watson M, Stefanick DF, Shaughnessy DT, Taylor JA, Wilson SH. 2008. XRCC1 and DNA polymerase beta in cellular protection against cytotoxic DNA single-strand breaks. Cell Res 18(1):48-63.

Hu Z, Ma H, Chen F, Wei Q, Shen H. 2005. XRCC1 polymorphisms and cancer risk: a meta-analysis of 38 case-control studies. Cancer Epidemiol Biomarkers Prev 14(7):1810-1818.

Hung RJ, Hall J, Brennan P, Boffetta P. 2005. Genetic polymorphisms in the base excision repair pathway and cancer risk: a HuGE review. Am J Epidemiol 162(10):925-942.

IARC (International Agency for Research on Cancer). 1982. Miscellaneous Pesticides. IARC Monograph Eval Carcinog Risk Hum 30.

Krokan HE, Bjoras M. 2013. Base excision repair. Cold Spring Harb Perspect Biol 5(4):a012583.

Kubota Y, Nash RA, Klungland A, Schar P, Barnes DE, Lindahl T. 1996. Reconstitution of DNA base excision-repair with purified human proteins: interaction between DNA polymerase beta and the XRCC1 protein. EMBO J 15(23):6662-6670.

Lebailly P, Mirey G, Herin F, Lecluse Y, Salles B, Boutet-Robinet E. 2015. DNA damage in B and T lymphocytes of farmers during one pesticide spraying season. Int Arch Occup Environ Health 88(7):963-972.

Legator MS. 1969. Mutagenic effects of aflatoxin. J Am Vet Med Assoc 155(12):2080-2083.

Liu Q, Guntuku S, Cui XS, Matsuoka S, Cortez D, Tamai K, Luo G, Carattini-Rivera S, DeMayo F, Bradley A, Donehower LA, Elledge SJ. 2000. Chk1 is an essential kinase that is regulated by Atr and required for the G(2)/M DNA damage checkpoint. Genes Dev 14(12):1448-1459.

Lozowicka B. 2015. Health risk for children and adults consuming apples with pesticide residue. Sci Total Environ 502:184-198.

McCauley LA, Lasarev M, Muniz J, Nazar Stewart V, Kisby G. 2008. Analysis of pesticide exposure and DNA damage in immigrant farmworkers. J Agromedicine 13(4):237-246.

Moriya M, Kato K, Shirasu Y. 1978. Effects of cysteine and a liver metabolic activation system on the activities of mutagenic pesticides. Mutat Res 57(2):259-263.

O'Neill JP, Forbes NL, Hsie AW. 1981. Cytotoxicity and mutagenicity of the fungicides captan and folpet in cultured mammalian cells CHO/HGPRT system). Environ Mutagen 3(3):233-237.

Ohta T, Tokishita S, Tsunoi R, Ohmae S, Yamagata H. 2002. Characterization of Trp(+) reversions in Escherichia coli strain WP2uvrA. Mutagenesis 17(4):313-316.

Presutti R, Harris SA, Kachuri L, Spinelli JJ, Pahwa M, Blair A, Zahm SH, Cantor KP, Weisenburger DD, Pahwa P, McLaughlin JR, Dosman JA, Freeman LB. 2016. Pesticide exposures and the risk of multiple myeloma in men: An analysis of the North American Pooled Project. Int J Cancer 139(8):1703-1714.

Pritchard D, Lappin G. 1991. Captan: DNA binding study in the mouse. Report No CTL/P/3380 from ICI Central Toxicology Laboratory, Alderley Park, Macclesfield, Cheshire, United Kingdom Second Amendment : September 22. 
Provan W, Eyton-Jones H. 1996. The bioavailability of captan to the duodenum of CD-1 mice following dietary administration. Report No CTL/R/1260 from Zeneca, Inc, Central Toxicology Laboratory, Alderley Park, Macclesfield, Cheshire, United Kingdom January 24.

Provan WM, Eyton-Jones H, Lappin G, Pritchard D, Moore RB, Green T. 1995. The incorporation of radiolabelled sulphur from captan into protein and its impact on a DNA binding study. Chem Biol Interact 96(2):173-184.

Rahden-Staron I. 2002. The inhibitory effect of the fungicides captan and captafol on eukaryotic topoisomerases in vitro and lack of recombinagenic activity in the wing spot test of Drosophila melanogaster. Mutat Res 518(2):205-213.

Ray Chaudhuri A, Hashimoto Y, Herrador R, Neelsen KJ, Fachinetti D, Bermejo R, Cocito A, Costanzo $\mathrm{V}$, Lopes M. 2012. Topoisomerase I poisoning results in PARP-mediated replication fork reversal. Nat Struct Mol Biol 19(4):417-423.

Saldivar JC, Cortez D, Cimprich KA. 2017. The essential kinase ATR: ensuring faithful duplication of a challenging genome. Nat Rev Mol Cell Biol 18(10):622-636.

Schultz LB, Chehab NH, Malikzay A, Halazonetis TD. 2000. p53 binding protein 1 (53BP1) is an early participant in the cellular response to DNA double-strand breaks. J Cell Biol 151(7):13811390.

Selsky C, Matheson D. 1981. The association of captan with mouse and rat deoxyribonucleic acid. Farmington, CT: Stauffer Report no T-10435.

Snyder RD. 1992. Effects of Captan on DNA and DNA metabolic processes in human diploid fibroblasts. Environ Mol Mutagen 20(2):127-133.

Swenberg JA, Petzold GL, Harbach PR. 1976. In vitro DNA damage/alkaline elution assay for predicting carcinogenic potential. Biochem Biophys Res Commun 72(2):732-738.

Taniguchi T, Garcia-Higuera I, Andreassen PR, Gregory RC, Grompe M, D'Andrea AD. 2002. S-phasespecific interaction of the Fanconi anemia protein, FANCD2, with BRCA1 and RAD51. Blood 100(7):2414-2420.

Tezuka H, Ando N, Suzuki R, Terahata M, Moriya M, Shirasu Y. 1980. Sister-chromatid exchanges and chromosomal aberrations in cultured Chinese hamster cells treated with pesticides positive in microbial reversion assays. Mutat Res 78(2):177-191.

Thompson CM, Wolf JC, McCoy A, Suh M, Proctor DM, Kirman CR, Haws LC, Harris MA. 2017. Comparison of Toxicity and Recovery in the Duodenum of B6C3F1 Mice Following Treatment with Intestinal Carcinogens Captan, Folpet, and Hexavalent Chromium. Toxicol Pathol 45(8):1091-1101.

Thompson LH, Brookman KW, Dillehay LE, Carrano AV, Mazrimas JA, Mooney CL, Minkler JL. 1982. A CHO-cell strain having hypersensitivity to mutagens, a defect in DNA strand-break repair, and an extraordinary baseline frequency of sister-chromatid exchange. Mutat Res 95(2-3):427440.

Vignard J, Mirey G, Salles B. 2013. lonizing-radiation induced DNA double-strand breaks: a direct and indirect lighting up. Radiother Oncol 108(3):362-369.

Zdzienicka MZ, van der Schans GP, Natarajan AT, Thompson LH, Neuteboom I, Simons JW. 1992. A Chinese hamster ovary cell mutant (EM-C11) with sensitivity to simple alkylating agents and a very high level of sister chromatid exchanges. Mutagenesis 7(4):265-269.

\section{Conflict of Interest statement}

The authors declare that there are no conflicts of interest. 


\section{Figure legends}

Fig. 1. Hypersensitivity to captan in XRCC1-deficient mammalian cells. (A) Left Panel: HeLa cells were transfected with scramble (Ctrl) or XRCC1 siRNA and XRCC1 protein level was analysed by Western blot. GAPDH is shown as a loading control. Right panel: clonogenic survival of HeLa cells transfected with scramble (Ctrl) or XRCC1 siRNA and exposed to captan. Results are the mean \pm SEM of at least four independent experiments. ( $* \mathrm{P}<0.05)$. (B) Clonogenic survival of AA8) and EM9 CHO cells after treatment with captan. Results represent the mean \pm SEM of three independent experiments. (***P $<0.001$ ). (C) Micronucleus frequency after captan treatment for 24 hours observed in AA8 and EM9 cells. Data are expressed as the mean \pm SEM of four independent experiments. ( $* \mathrm{P}<0.05$, *** $\mathrm{P}<0.001)$. (D) DNA damage evaluated by alkaline (-Fpg) and Fpg-modified comet assay (+Fpg) after $1 \mu \mathrm{M}$ captan treatment for 2 hours in AA8 or EM9 CHO cells. Results are mean \pm SEM of three independent experiments. (***P $<0.001$ versus non-treated). (E) DNA damage evaluated by Fpg-modified comet assay, represented as increase of Net Fpg-sensitive sites (above the control treatment cells), immediately after 2 hours of captan treatment $(1 \mu \mathrm{M})($ time $=0)$ and after a recovery time of 60 minutes. Results are mean \pm SEM of six independent experiments. $(* * \mathrm{P}<0.01)$.

Fig. 2. Importance of replicative stress signalling in response to captan. (A) Representative images of $\gamma \mathrm{H} 2 \mathrm{AX}$ and 53BP1 immunostaining of HeLa cells treated with $20 \mu \mathrm{M}$ of captan for 2 hours. Asterisks indicate cells scored positive for $\gamma \mathrm{H} 2 \mathrm{AX}$ or 53BP1 staining. Scale bar $=20 \mu \mathrm{m}$. (B) Quantification of HeLa cells positive for $\gamma \mathrm{H} 2 \mathrm{AX}$ or 53BP1 signal. $(* * \mathrm{P}<0.01$,

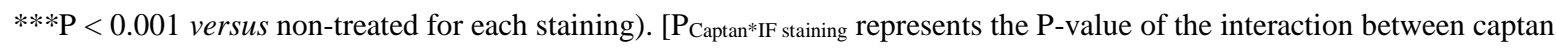
treatment and staining $(\gamma \mathrm{H} 2 \mathrm{AX}$ or 53BP1) showing a significant higher staining of $\gamma \mathrm{H} 2 \mathrm{AX}$ than 53BP1 induced by captan]. (C) p-Chk1, Chk1 and FANCD2 immunoblots of soluble extracts from HeLa cells treated for 2 hours with captan $20 \mu \mathrm{M}$ or non-treated cells. (D) Left Panel: HeLa cells were transfected with scramble (Ctrl) or ATR siRNA and ATR protein level was analysed by Western blot. Lamin C is shown as a loading control. Right panel: Clonogenic survival of HeLa cells transfected with scramble (Ctrl siRNA) or ATR siRNA and exposed to captan. Results are the mean \pm SEM of at least three independent experiments. ( $* \mathrm{P}<0.05$, $* * \mathrm{P}<0.01)$. (E) Micronucleus frequency after $10 \mu \mathrm{M}$ captan treatment for 24 hours measured in HeLa control (scramble siRNA) and ATR siRNA. Data are expressed as mean \pm SEM of three independent experiments.

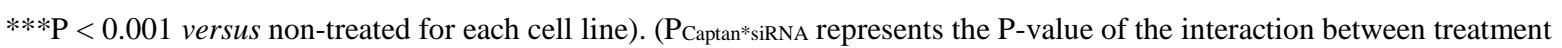
and siRNA). (F) Left panel: Representative images of 53BP1 immunostaining of HeLa cells transfected with scramble (Ctrl siRNA) or ATR siRNA and treated with $10 \mu \mathrm{M}$ of captan for 2 hours. Scale bar $=50 \mu \mathrm{m}$. Right panel: Quantification of HeLa cells positive for 53BP1 foci formation. Data represent the mean \pm SEM of three independent experiments. $(* * * \mathrm{P}<$

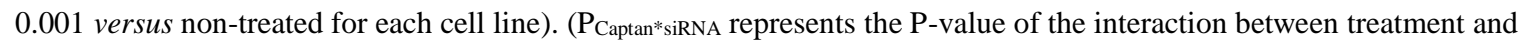
SiRNA).

Fig. 3. Captan decreases replication speed and fork restart independently of XRCC1. (A) Left panel: Representative flow cytometry of AA8 and EM9 CHO cells treated or not with $10 \mu \mathrm{M}$ captan for 2 hours followed by $\gamma \mathrm{H} 2 \mathrm{AX}$ and DAPI staining. Right panel: Quantification of $\gamma \mathrm{H} 2 \mathrm{AX}$ positive cells. Data represent the mean $\pm \mathrm{SEM}$ of four independent experiments. (***P 


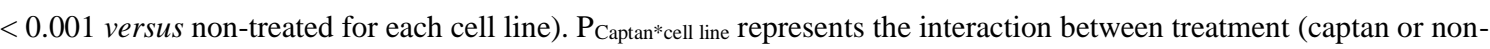
treated) and cell line (AA8 or EM9 CHO cell lines). (B) Left panel: Representative flow cytometry of AA8 and EM9 CHO cells treated or not with $10 \mu \mathrm{M}$ captan for 2 hours followed by cell cycle analysis. EdU incorporation is plotted against the cellular DNA content (DAPI). Quantification of G1, S and G2 cell population (boxed) is indicated. Right panel: Data represent the percentage of EdU-positive (upper panel) and EdU-negative cells (lower panel) in the S phase (mean \pm SEM of three independent experiments). (*P $<0.05$, **P $<0.01$ versus non-treated for each cell line). (C) Upper panel: Replication fork speed was analysed by DNA fibre assay. AA8 and EM9 CHO cell lines were treated or not with $10 \mu \mathrm{M}$ of captan during IdU incorporation. IdU track length was determined. Middle panel: Representative images of replication tracks: CldU (red) and IdU (green) (Original magnification X40, Scale bar $=10 \mu \mathrm{m}$ ). Lower panel: Horizontal red lines represent the median (*** $\mathrm{P}<0.001)$. This experiment is representative of two independent experiments. (D) Quantification of replication fork restart in AA8 and EM9 CHO cell lines after captan treatment. Cells were treated or not with $10 \mu \mathrm{M}$ of captan during CldU incorporation, and IdU track length was analysed. Middle panel: Representative images of replication tracks: CldU (red) and IdU (green) (Original magnification X40, Scale bar $=10 \mu \mathrm{m})$. Lower panel : Horizontal red lines represent the median $(* * * \mathrm{P}$ $<0.001)$.

Fig. 4. The fungicide captan induces two independent genotoxic effects. Left part: captan induces base modifications that require XRCC1 to be repaired. Right part: captan is also responsible for a replicative stress, impacting replicative-fork speed and leading to double-strand breaks. Both effects contribute to the establishment of genomic instability. 


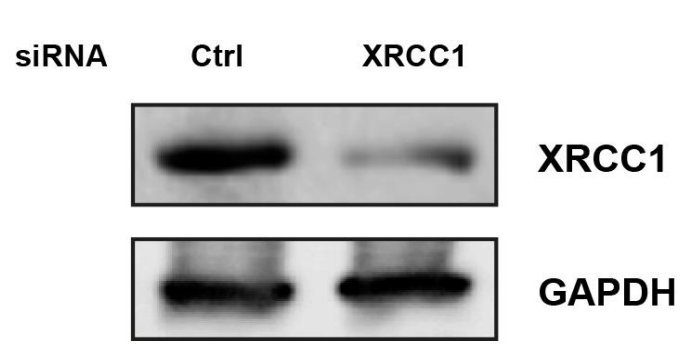

B

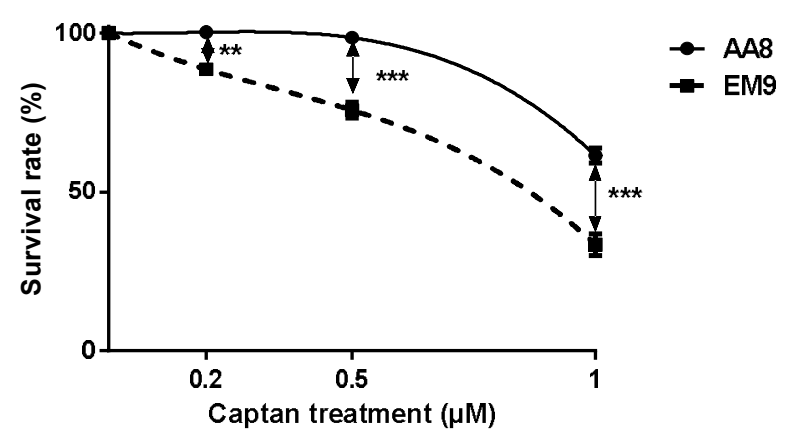

D

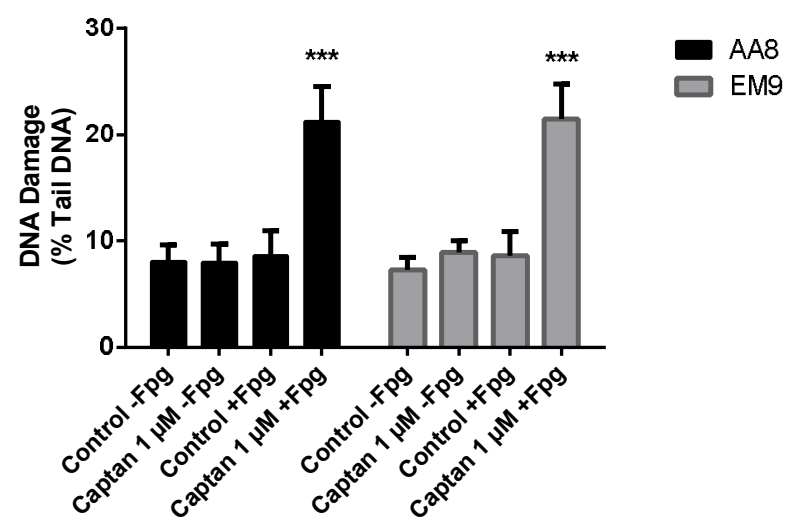

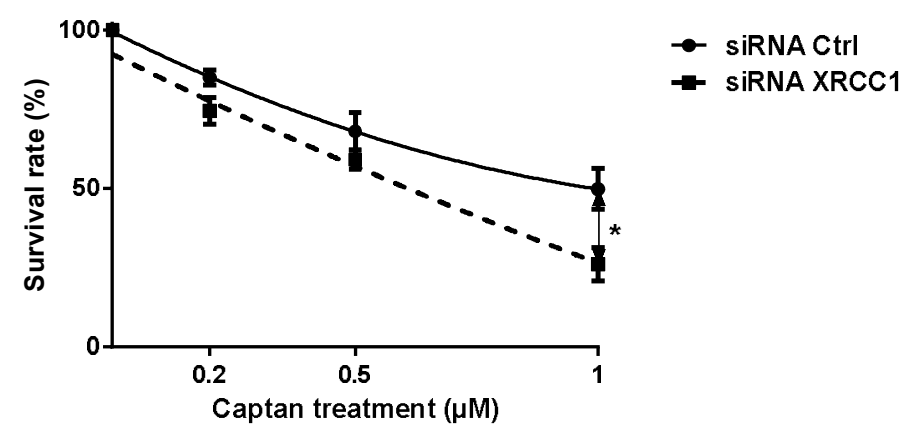

C

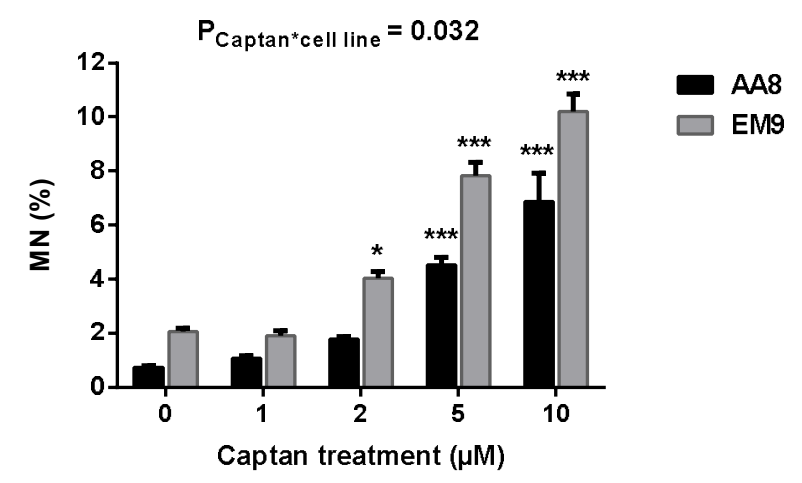

E

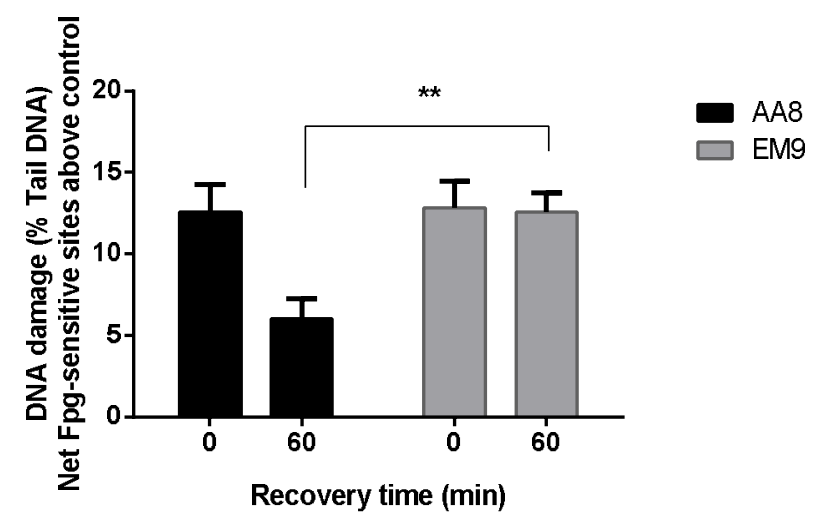

Fig. 1 

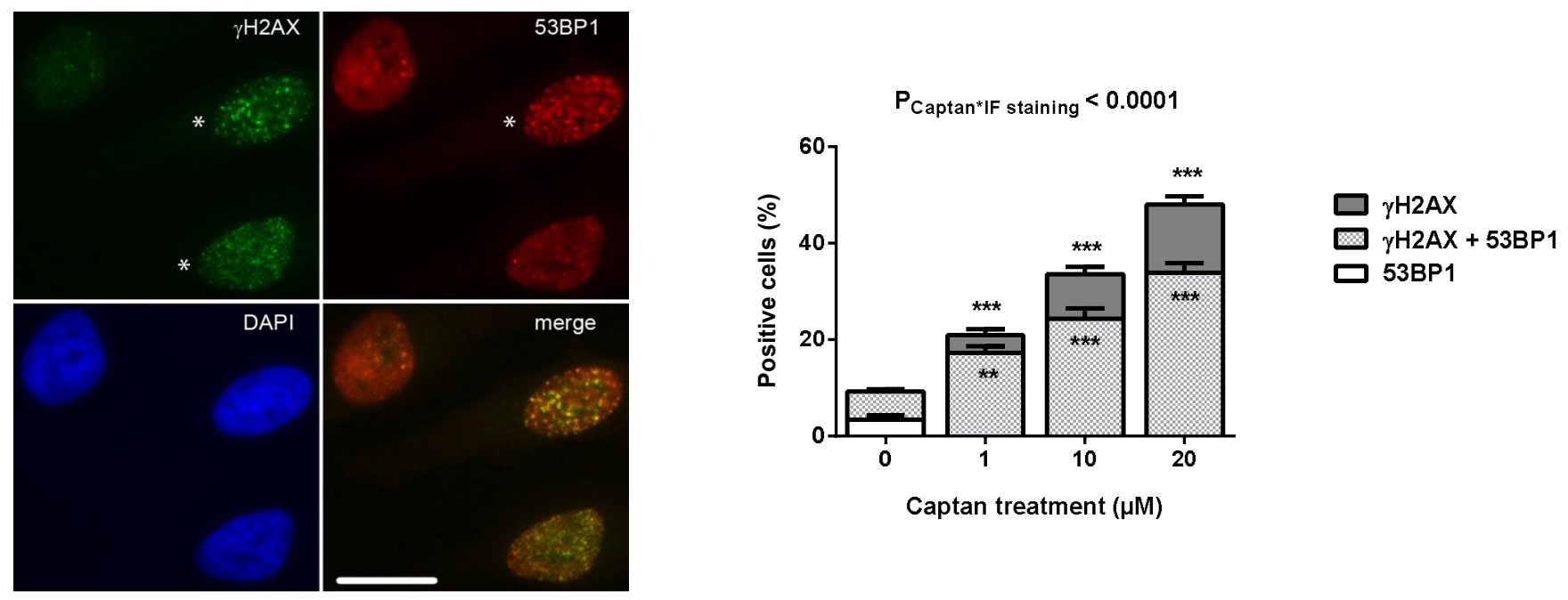

C

Non-treated Captan

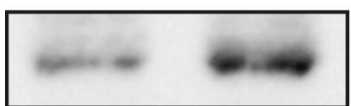

pChk1

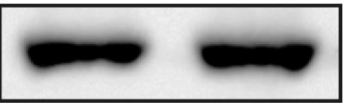

Chk1

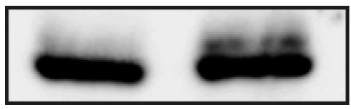

FANCD2

E

- siRNA Ctrl

D SIRNA ATR

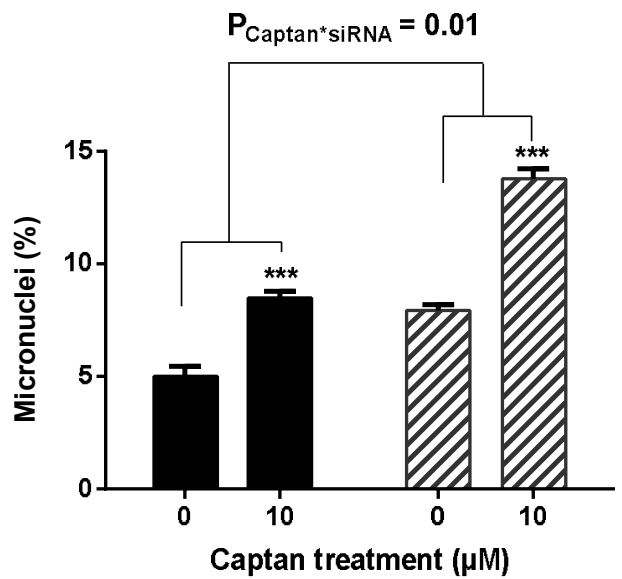

D

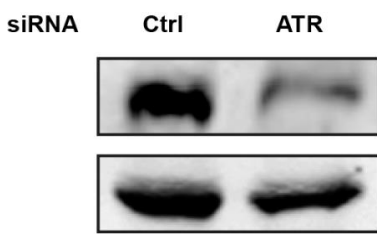

Fig. 2
ATR

Lamin C

Captan

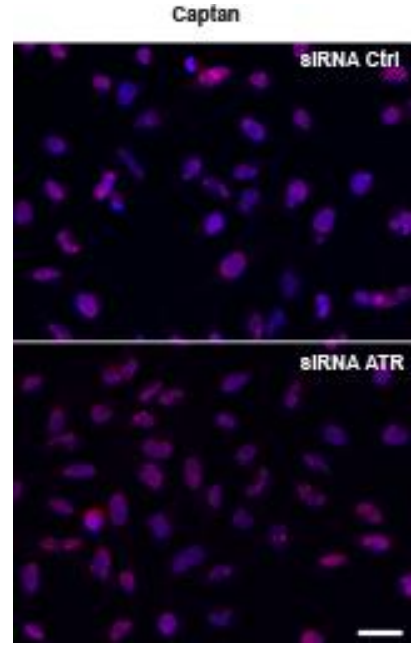

$\rightarrow$ siRNA Ctrl

- - siRNA ATR

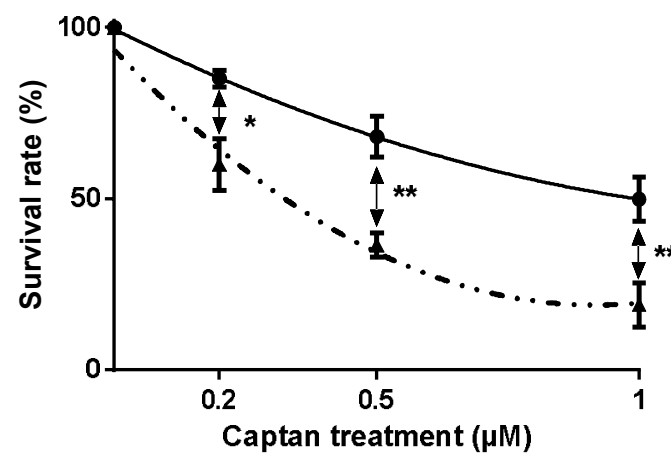

F

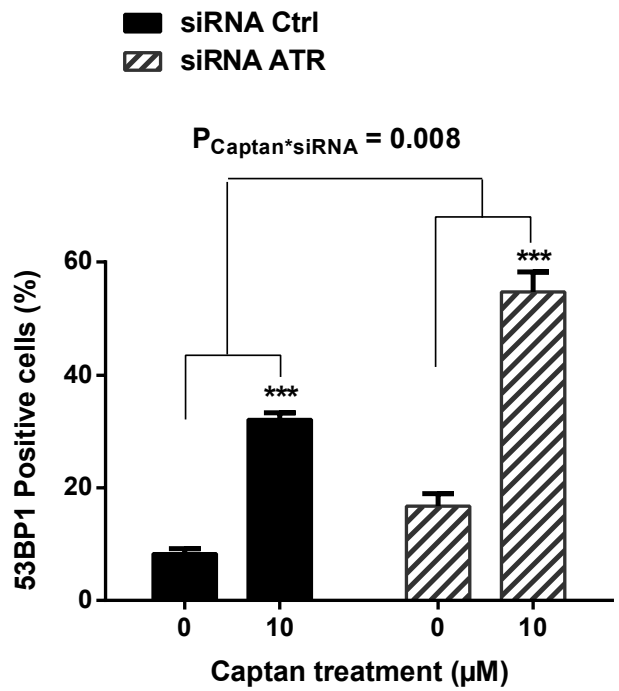


A

Non-treated

Captan

AA8
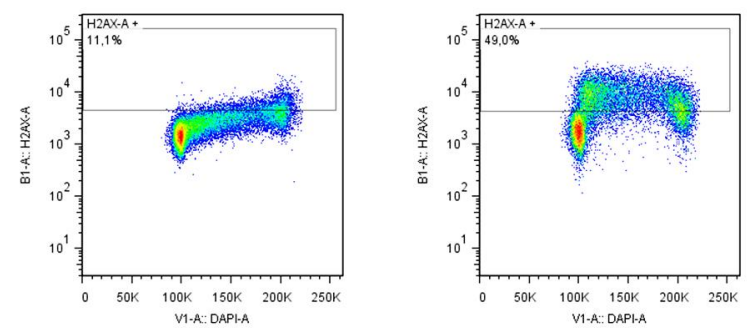

EM9
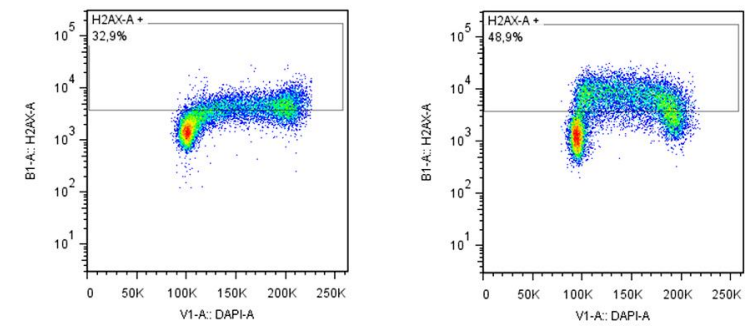

B
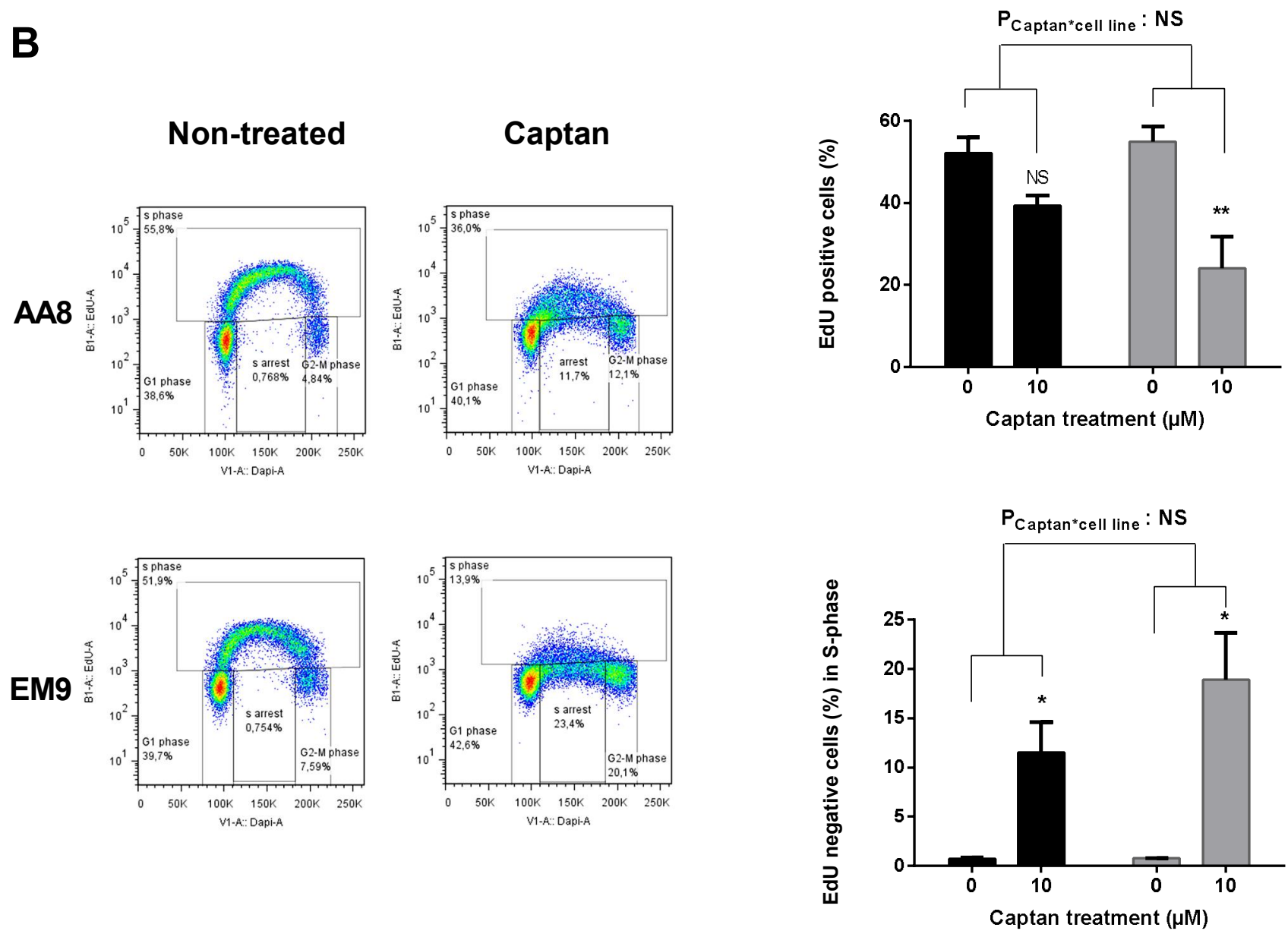

- AA8

$\square$ EM9

Fig. 3 
C
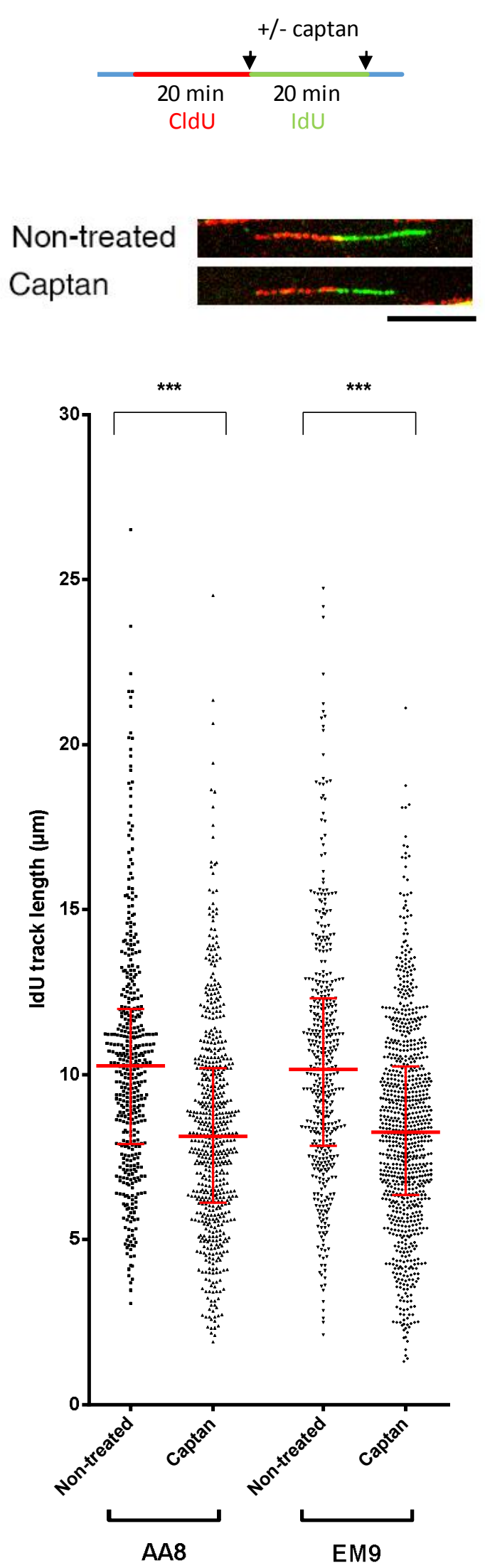

D

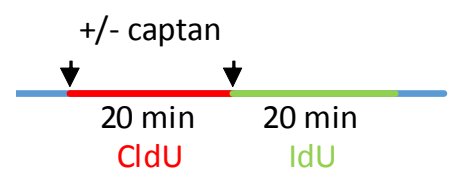

Non-treated

Captan
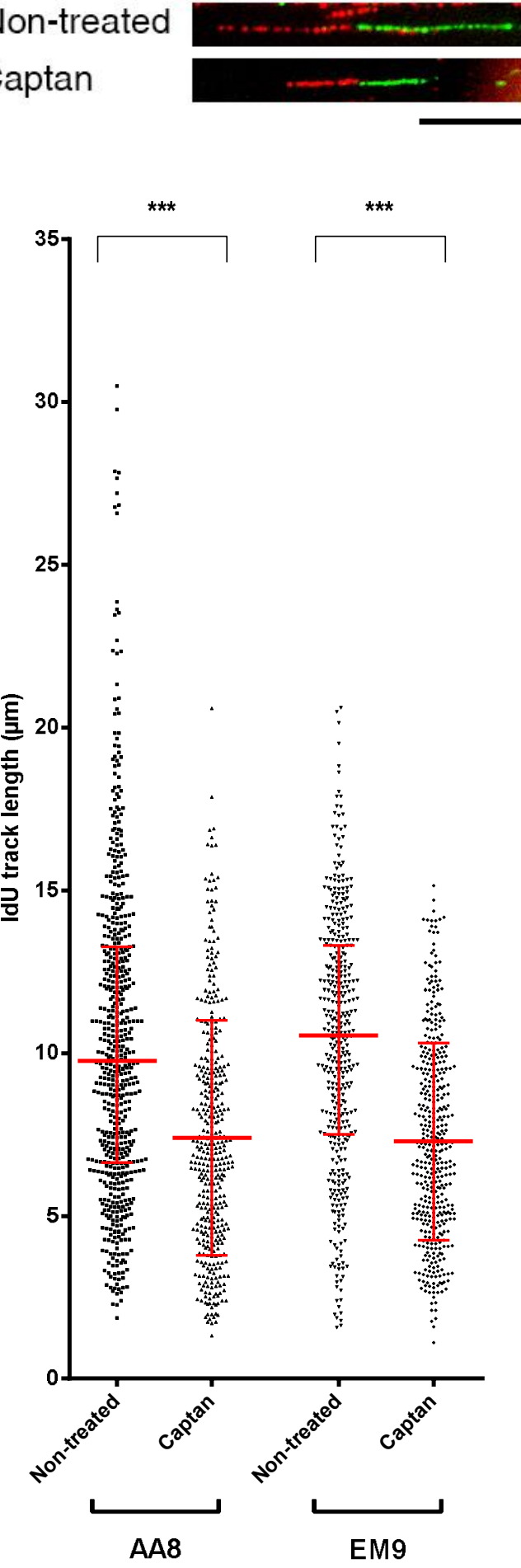

Fig. 3 
Captan genotoxicity in mammalian cells

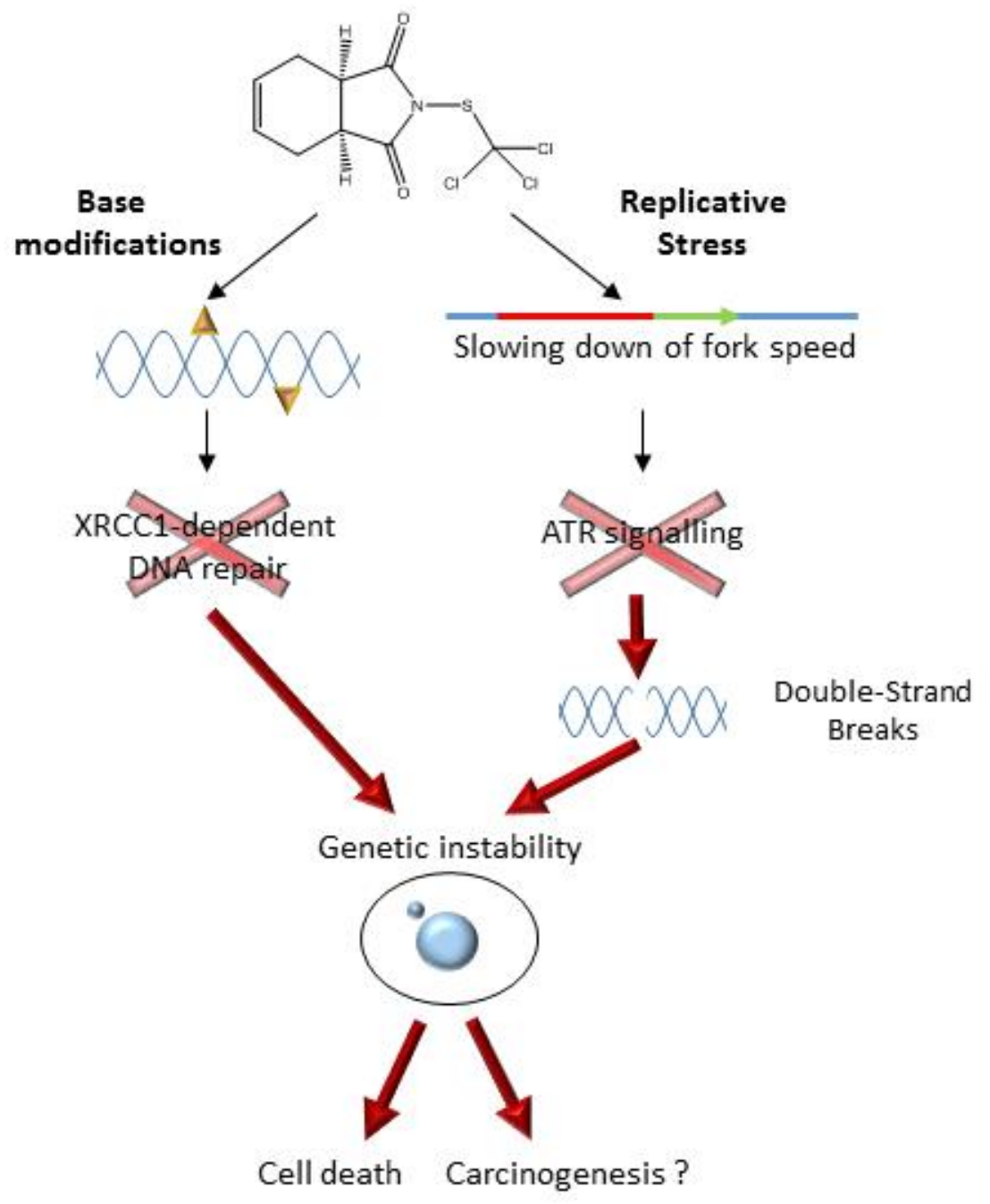

Fig. 4 